\title{
Opinions of parents concerning childhood vaccine refusal and factors affecting vaccination in Konya
}

\author{
(ㄴ) Hüseyin İlter', (ㄴ Lütfi Saltuk Demir ${ }^{2}$ \\ ${ }^{1}$ Ministry of Health General Directorate of Public Health, Ankara, Turkey \\ ${ }^{2}$ Necmettin Erbakan University Faculty Meram of Medicine, Department of Public Health, Konya, Turkey
}

Date submitted:

04.08.2020

Date accepted:

05.10.2020

Online publication date: 15.06.2021

\section{Corresponding Author:}

Hüseyin İlter, M.D., Ministry of Health General Directorate of Public Health, Ankara, Turkey

ORCID:

orcid.org/0000-0002-4452-8902

Keywords: Vaccination, vaccine refusal, anti-vaccination movement, immunization

\begin{abstract}
Aims: The purpose of this study was to reveal the opinions, knowledge, and attitudes of parents in Konya, who refuse vaccination, concerning vaccine refusal.

Methods: The study has a cross-sectional design. The research data were collected in 2019 using a survey form developed by the researchers. The survey form was filled out by the parents of children in the 0-4 age group who had not been vaccinated in Konya and its districts in 2017 . We were able to reach 801 out of 923 children who had not been vaccinated and still living in Konya. The parents of 590 children (73.7\%) who agreed to participate in the study were interviewed.

Results: The most commonly refused type of vaccination was hepatitis $A$, whereas the least was hepatitis $B$. The most common reasons for vaccine refusal were believing that vaccines were not safe (63.9\%), not believing that vaccines were useful and necessary (57.6\%), and not trusting vaccines because they were produced overseas (47.3\%). While $65.9 \%$ of the families reported that a family health worker tried to convince them to have their children vaccinated, $32.4 \%$ reported that a family physician tried to convince them. $48.8 \%$ of the parents believed that vaccines caused autism. $70.0 \%$ of the parents named their family physician as their source of information, $65.4 \%$ named internet/social media.

Conclusions: The families had difficulty with trusting health workers and disregarded the information provided by health workers. Additionally, it was found that gynecologists did not sufficiently inform pregnant women regarding vaccination during the follow-up process.
\end{abstract}

\section{Introduction}

Immunization is a very important and cost effective primary health care service for the protection of individual and public health (1). For this reason, it is regarded as the most significant public health achievement of the $20^{\text {th }}$ century $(2,3)$.

Vaccines are quite safe and effective in developing the immunity of the individual and the society. However, they are not $100 \%$ effective and safe (4). Vaccination does not provide immunity in $1-5 \%$ of cases. There is also a group that cannot get vaccinated consisting of, for example, those who are unable to access health care services, those who have certain diseases, or those whose immunity is impaired due to medication. The addition of vaccination refusers to this group who cannot develop an immunity against vaccine-preventable diseases creates a non-vaccinated, and therefore unprotected segment in the society. This is a significant risk in terms of collective immunity. Failure to reach an adequate level of vaccination as a society leads to increased risk and paves the way for disease outbreaks.

Reservations concerning vaccines have emerged with the introduction of vaccination. In parallel with the developments around the world, the anti-vaccination movement has emerged in Turkey as well. However, after the decision of the Constitutional Court on 2015, the number of families refusing to vaccinate their children increased rapidly, reaching from 183 in 2011 and 980 in 2013 to 5.400 in 2015, 12,000 in 2016, and exceeding 23,000 in 2017 (5).

Increasing number of vaccine hesitation or refusal cases poses a serious risk not only for the individual, but also for the society due to the loss of gains related to children's health in

๑Copyright 2021 by the University of Health Sciences Turkey, Gülhane Faculty of Medicine / Gülhane Medical Journal published by Galenos Publishing House. 
particular. Due to the risk of re-emergence of diseases that are no longer seen or rarely seen, World Health Organization (WHO) designated vaccine hesitancy as one of the ten leading threats to global health in 2019.

The Konya province of Turkey is one of the leading cities in terms of vaccine refusal, which is a growing problem in the entire world as well as Turkey. According to TurkStat birth statistics, the vaccine refusal rate in the province of Konya in 2017 was found to be $2.6 \%$ (6). The purpose of this study was to identify the facts by reaching the parents living in Konya who had refused or hesitated to have their children vaccinated in 2017, to compare findings with similar studies conducted in Turkey, and to suggest possible solutions.

\section{Methods}

The study has a cross-sectional design. The research data were collected in March-August 2019 using a 4-section and 26item survey form developed by the Necmettin Erbakan University Faculty of Medicine Public Health Department researchers. For the purposes of the study, the parents of children in the 0-4 age group living in Konya and its districts who were registered by family physicians and not vaccinated in 2017 due to vaccine refusal or other various reasons were reached through family health centers and the survey was administered electronically.

No sample selection was performed. In Konya, there were 923 children, who were not vaccinated in 2017 due to vaccine refusal or hesitancy. The parents of 122 of these children were excluded from the study since they could not be reached. The parents of 211 of the remaining 801 children refused to respond to the survey and therefore did not participate in the study. The study was completed by interviewing the parents of $590(73.7 \%)$ children living in Konya, who we were able to reach.

\section{Statistical Analysis}

The data obtained from the survey administration were imported to the database created in Statistical Package for Social Sciences version 23.0 to perform the statistical analysis. Mean \pm standard deviation was used for numerical data, frequency and percentage were used for categorical data, and the chi-square test was used for comparisons between categorical variables. The statistical significance level was set at $p<0.05$.

\section{Results}

The distribution of non-vaccinated children by district is shown in Figure 1, and the density map obtained by comparing the district populations with the number of vaccine refusal cases is shown in Figure 2. $61.9 \%$ of the families with vaccine refusal or hesitancy were living in the central districts (Karatay, Meram, Selcuk), whereas $38.1 \%$ were living in the districts out of the center.

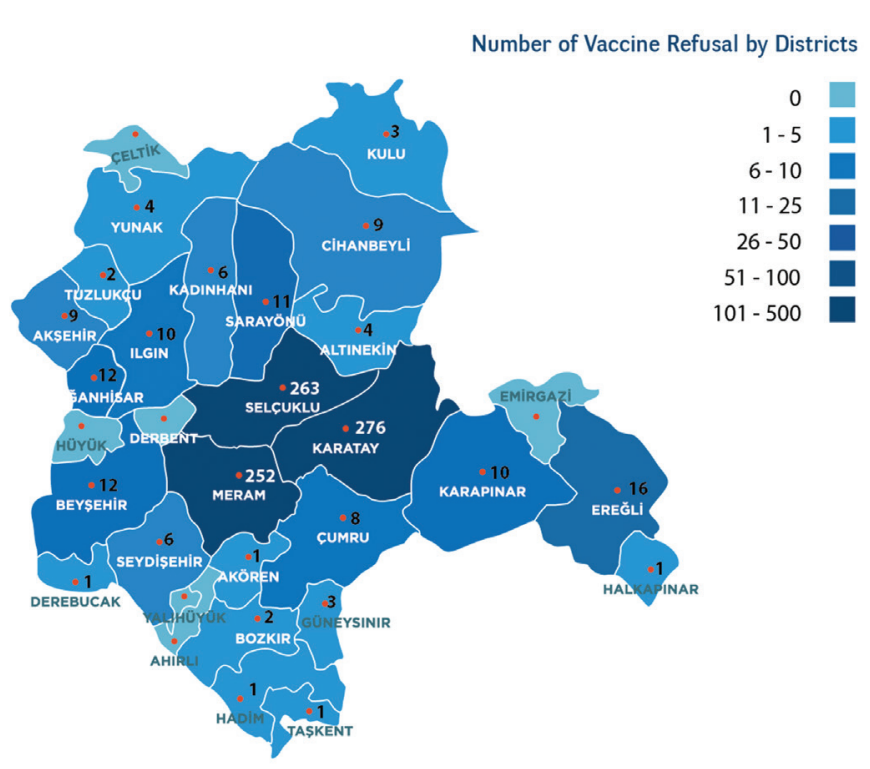

Figure 1. Distribution map of families refusing vaccination by district, Konya-2019

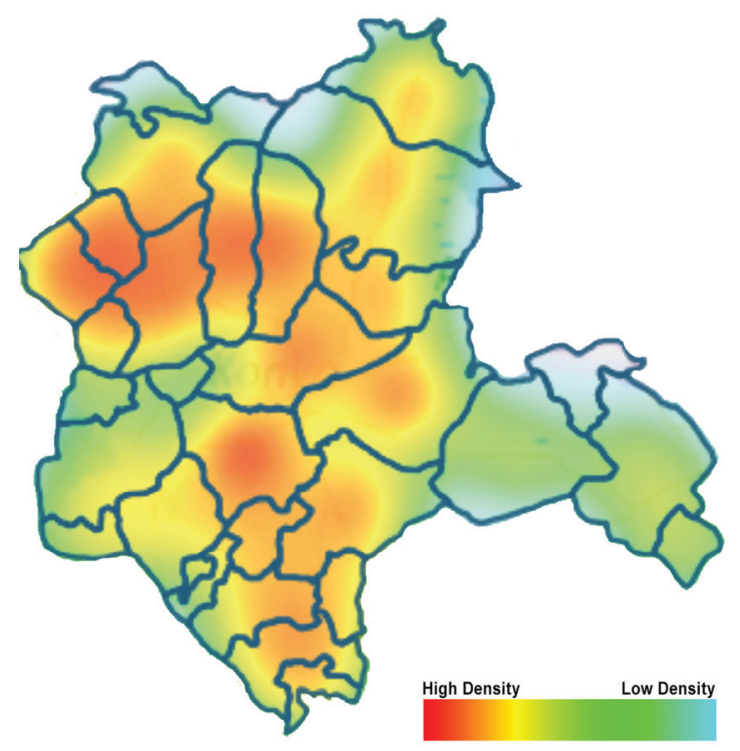

Figure 2. Density map based on the ratio of families refusing vaccination to district population, Konya-2019

Four hundred seventy-eight (81.0\%) mothers and 112 $(19.0 \%)$ fathers were interviewed in the study. The mean age of the mothers was $30.84 \pm 5.59$ years and the age interval was found to be from 21 to 47 years. The mean age of the fathers was $33.81 \pm 5.62$ years and the youngest was 21 years old, while the oldest was 51 years old. The age distribution, education and employment status of the parents are shown in Table 1. $28.3 \%$ of the employed mothers and $7.6 \%$ of the employed fathers stated that they were working in the health industry.

$37.9 \%$ of families with multiple children stated that they refused to have their other children vaccinated as well. The vaccine refusal was the most common for hepatitis $A$, 
measles, mumps, and rubella (MMR) combination vaccine, and chickenpox vaccine, and the least common for hepatitis $B$, Bacillus Calmette-Guérin, and Td vaccines (Table 2).

The most common reason for vaccine refusal was found to be believing that vaccines were not safe, followed by not believing that vaccines were useful and necessary, not trusting vaccines because they were produced overseas, believing that vaccines contained religiously forbidden ingredients such as pork products, and being influenced by negative news stories in the media about vaccines (Table 3 ). The majority of the participants stated that they decided against vaccination jointly with their partners $(67.5 \%)$. All of the vaccine refusers reported

\begin{tabular}{lllll|}
\hline $\begin{array}{l}\text { Table 1. Socio-demographic } \\
\text { Konya-2019 }\end{array}$ & \multicolumn{3}{l}{ characteristics } & of parents, \\
\hline & \multicolumn{5}{c}{ Mother } & \multicolumn{3}{l}{ Father } \\
\cline { 2 - 5 } & $\begin{array}{l}\text { Number } \\
\text { (n) }\end{array}$ & $\begin{array}{l}\text { Percentage } \\
(\%)\end{array}$ & $\begin{array}{l}\text { Number } \\
\text { (n) }\end{array}$ & $\begin{array}{l}\text { Percentage } \\
(\%)\end{array}$ \\
\hline Educational status & & 1 & 0.2 \\
\hline Literate & 11 & 1.9 & 54 & 9.2 \\
\hline Primary school & 118 & 20.0 & 59 & 10.0 \\
\hline Middle school & 89 & 15.1 & 117 & 19.8 \\
\hline High school & 167 & 28.3 & 331 & 56.1 \\
\hline Undergraduate & 187 & 31.7 & 28 & 4.7 \\
\hline Postgraduate & 18 & 3.1 & 590 & 100.0 \\
\hline Total & 590 & 100.0 & & \\
\hline Employment status & & 556 & 94.2 \\
\hline Full-time & 128 & 21.7 & 20 & 3.4 \\
\hline Part-time & 39 & 6.6 & 14 & 2.4 \\
\hline Unemployed & 423 & 71.7 & 590 & 100.0 \\
\hline Total & 590 & 100.0 & & \\
\hline
\end{tabular}

that a health worker tried to convince them otherwise. It was a family health worker for $65.9 \%$, a family physician for $32.4 \%$, and pediatrician for $1.7 \%$.

Opinions of parents regarding vaccination are summarized in Table 4 and information sources on childhood vaccines are seen in Table 5.

$4.2 \%$ of participants reported that they were not informed about vaccines by their family physicians or family health workers during pregnancy, $24.2 \%$ reported that they were not informed by their gynecologist during pregnancy follow-ups, and $19.0 \%$ reported that they were not informed by health workers in the hospital where they gave birth.

There were some differences of opinion between the mothers and fathers participating in the study. $74.1 \%$ of the fathers believed that recommended vaccines served the economic interests of drug companies compared to $68.8 \%$ of the mothers $(p=0.016)$. Similarly, more fathers than mothers believed that vaccines contained religiously forbidden ingredients such as pork products $(p=0.023)$. Additionally, more fathers $(18.8 \%)$ than mothers stated that they were not accurately informed when they decided not to have their children vaccinated $(p=0.020)$.

It was found that more parents with undergraduate and postgraduate education believed that vaccines caused autism than the parents with middle school/high school and primary school education $(p=0.003)$. Parents with middle school and high school education stated that personnel that performed the vaccination allocated sufficient time to clear their doubts concerning vaccination $(p=0.003)$. More parents with undergraduate and postgraduate education agreed with the statement, "Personnel that perform the vaccination have sufficient knowledge about vaccines" $(p=0.001)$.

Table 2. Status of children whose families refuse vaccination according to Extended Immunization Program, Konya-2019

\begin{tabular}{|c|c|c|c|c|c|c|}
\hline & $\begin{array}{l}\text { Vaccinated } \\
\text { on time }\end{array}$ & $\begin{array}{l}\text { Not vaccinated, } \\
\text { but will be }\end{array}$ & $\begin{array}{l}\text { Will not be } \\
\text { vaccinated/l am } \\
\text { not sure }\end{array}$ & $\begin{array}{l}\text { I do not know/ } \\
\text { I do not remember }\end{array}$ & No response & Total \\
\hline Vaccine & $\mathrm{n}(\%)$ & $\mathrm{n}(\%)$ & n (\%) & $\mathrm{n}(\%)$ & $\mathrm{n}(\%)$ & $\mathrm{n}(\%)$ \\
\hline Hepatitis B & $146(24.7)$ & $121(20.5)$ & $183(31.0)$ & $15(2.5)$ & $125(21.2)$ & $590(100.0)$ \\
\hline BCG & $152(25.8)$ & $21(3.6)$ & $230(39.0)$ & $11(1.9)$ & $176(29.8)$ & $590(100.0)$ \\
\hline DTaP-IPV-Hib & $69(11.7)$ & $105(17.8)$ & $261(44.2)$ & $9(1.5)$ & $146(24.7)$ & $590(100.0)$ \\
\hline MMR & $81(13.7)$ & $26(4.4)$ & $295(50.0)$ & $7(1.2)$ & $181(30.7)$ & $590(100.0)$ \\
\hline DTaP-IPV & $41(6.9)$ & $40(6.8)$ & $265(44.9)$ & $15(2.5)$ & $229(38.8)$ & $590(100.0)$ \\
\hline OPV & $55(9.3)$ & $63(10.7)$ & $286(48.5)$ & $12(2.0)$ & $174(29.5)$ & $590(100.0)$ \\
\hline $\mathrm{Td}$ & $24(4.1)$ & $21(3.6)$ & 237 (40.2) & $18(3.1)$ & $290(49.2)$ & $590(100.0)$ \\
\hline
\end{tabular}


It was observed that as the educational level increased, more parents agreed with the statement, "Recommended vaccines serve the interests of drug companies" $(p=0.002)$, "Health workers provide information about the benefits of vaccination, but not about risks" ( $p=0.001)$, "Mixed-combined vaccines limit the freedom to choose acceptable vaccines" $(p=0.001)$ and "Mixed-combined vaccines wear the immune system excessively" $(p=0.044)$. It was more common among the parents with undergraduate and postgraduate education to agree with the statements mentioned above. More parents with middle school/high school education agreed with the statement, "My pediatrician has sufficient knowledge about vaccines and allocates sufficient time for me" $(p=0.040)$.

It was more common among the parents with undergraduate and postgraduate education to use print sources and antivaccination groups compared to the parents with high school or lower education ( $p<0.001,<0.001$, respectively).

\section{Discussion}

Although the level of anti-vaccination sentiment varies from country to country, 182 out of 194 WHO member countries reported at least one case of vaccine hesitancy in 2014 (7). National and international studies indicate that vaccine refusal will continue to be a significant problem in terms of preventing infectious diseases around the world. The growing antivaccination movement may destroy the gains made in relation to vaccine-preventable diseases.

Studies around the world have revealed that some sociodemographic characteristics such as age, gender, education level, income level, and number of children may be associated with the anti-vaccination sentiment. In our study, a large portion of the parents who refused vaccination were found to be in the 25-34 age group and the vaccine refusal rate increased with increasing number of children. However, considering that vaccine refusal has rapidly grown after the Constitutional Court decision, we need comprehensive studies to reveal whether the growth in vaccine refusal is related to number of children or the decision of the Constitutional Court.

Vaccine refusal can be seen at all educational levels. $63.1 \%$ of the mothers and $80.6 \%$ of the fathers in our study had high school or higher education. The fact that some of the employed parents were working in the health care industry shows that the problem is not directly associated with education and profession and that knowledgeable families working the health care industry can also have concerns related to vaccines.

In some studies conducted in Turkey, a relationship was found between low educational level and incomplete vaccination $(8,9)$, and the vaccine refusal rate was found to be higher among families with two or more children (10). Knowing these associations well will be beneficial in terms of determining effective strategies in the fight against anti-vaccination movement.

In our study, the three most common vaccine refusal reasons were believing that vaccines were not safe, not believing that vaccines were useful and necessary, and not trusting vaccines because they were produced overseas. One study conducted in Croatia, France, Greece and Romania based on the views of health professionals revealed that vaccine hesitancy was present in all four countries, but there were differences in terms of ranking, and the most common concern was related to the

\begin{tabular}{|c|c|c|}
\hline & Number (n) & Percentage (\%) \\
\hline I do not believe that vaccines are safe. & 377 & 63.9 \\
\hline I do not trust vaccines because they are produced overseas. & 279 & 47.3 \\
\hline I believe that vaccines contain religiously forbidden ingredients (pork products, etc.). & 229 & 38.5 \\
\hline I have observed negative experiences in my social circle or with my other children after vaccination. & 90 & 15.3 \\
\hline I thought my child was too young. & 72 & 12.2 \\
\hline My child had a disease that prevented vaccination. & 53 & 9.0 \\
\hline I forgot the visit date/failed to show up for visit due to personal reasons. & 39 & 6.6 \\
\hline Health workers did not recommend me to participate in the vaccination program. & 3 & 0.5 \\
\hline Other ${ }^{* *}$ & 16 & 2.7 \\
\hline
\end{tabular}




\begin{tabular}{|c|c|c|c|c|c|}
\hline & $\begin{array}{l}\text { Strongly } \\
\text { agree } n(\%)\end{array}$ & $\begin{array}{l}\text { Agree } \\
\text { n (\%) }\end{array}$ & $\begin{array}{l}\text { Disagree } \\
\mathrm{n}(\%)\end{array}$ & $\begin{array}{l}\text { Strongly } \\
\text { disagree n (\%) }\end{array}$ & $\begin{array}{l}\text { I do not } \\
\text { know } n(\%)\end{array}$ \\
\hline $\begin{array}{l}\text { If we stop vaccination, diseases that have become very } \\
\text { uncommon will return. }\end{array}$ & $50(8.5)$ & $154(26.1)$ & $245(41.5)$ & $62(10.5 \%)$ & $79(13.4)$ \\
\hline $\begin{array}{l}\text { Childhood vaccinations are for the benefit of the entire } \\
\text { society. }\end{array}$ & $124(21)$ & 88 (14.9) & $264(44.7)$ & $60(10.2 \%)$ & $54(9.2)$ \\
\hline $\begin{array}{l}\text { Mandatory vaccines (e.g. measles) are more important than } \\
\text { non-mandatory vaccines (e.g. influenza). }\end{array}$ & $50(8.5)$ & 169 (28.6) & $232(39.3)$ & $54(9.2 \%)$ & $85(14.4)$ \\
\hline $\begin{array}{l}\text { I am scared of negative outcomes that may occur right after } \\
\text { vaccination. }\end{array}$ & $132(22.4)$ & 218 (36.9) & $162(27.5)$ & $38(6.4)$ & $40(6.8)$ \\
\hline $\begin{array}{l}\text { I am scared of possible damages that may occur years after } \\
\text { vaccination. }\end{array}$ & $147(24.9)$ & $226(38.3)$ & $158(26.8)$ & $33(5.6)$ & $26(4.4)$ \\
\hline I believe that vaccines cause autism. & $104(17.6)$ & $184(31.2)$ & $159(26.9)$ & $36(6.1)$ & $107(18.1)$ \\
\hline I believe that vaccines cause sterility. & $100(16.9)$ & $179(30.3)$ & 181(30.7) & $34(5.8)$ & $96(16.3)$ \\
\hline I believe that vaccines weaken the immune system. & $104(17.6)$ & $270(45.8)$ & $113(19.2)$ & $31(5.3)$ & $72(12.2)$ \\
\hline $\begin{array}{l}\text { If you lead a healthy lifestyle or use natural medicines, } \\
\text { vaccination is not necessary. }\end{array}$ & $134(22.7)$ & $252(42.7)$ & 75 (12.7) & $41(6.9)$ & $88(14.9)$ \\
\hline $\begin{array}{l}\text { It is too early to vaccinate a child right after birth and it would } \\
\text { be better to wait until the child older. }\end{array}$ & $131(22.2)$ & $185(31.4)$ & $125(21.2)$ & $45(7.6)$ & $104(17.6)$ \\
\hline $\begin{array}{l}\text { I believe that some vaccines are more dangerous than } \\
\text { infections that they prevent. }\end{array}$ & $100(16.9)$ & $238(40.3)$ & $136(23.1)$ & $32(5.4)$ & $84(14.2)$ \\
\hline $\begin{array}{l}\text { Recommended vaccines serve the interests of drug } \\
\text { companies. }\end{array}$ & $179(30.3)$ & $233(39.5)$ & $55(9.3)$ & $27(4.6)$ & $96(16.3)$ \\
\hline $\begin{array}{l}\text { I believe that numerous vaccines contain hazardous } \\
\text { substances (thiomersal, mercury). }\end{array}$ & $150(25.4)$ & $233(39.5)$ & $113(19.2)$ & $21(3.6)$ & $73(12.4)$ \\
\hline $\begin{array}{l}\text { I believe that vaccines contain religiously forbidden } \\
\text { ingredients such as pork products. }\end{array}$ & $127(21.5)$ & $201(34.1)$ & $116(19.7)$ & $48(8.1)$ & 98 (16.6) \\
\hline $\begin{array}{l}\text { When I decided against the vaccination of my child, I was not } \\
\text { accurately informed. }\end{array}$ & $23(3.9)$ & $43(7.3)$ & $299(50.7)$ & $183(31)$ & $42(7.1)$ \\
\hline $\begin{array}{l}\text { Health workers provide information about the benefits of } \\
\text { vaccination, but not about risks. }\end{array}$ & $82(13.9)$ & $60(27.1)$ & $217(36.8)$ & 75 (12.7) & $56(9.5)$ \\
\hline $\begin{array}{l}\text { I believe that free vaccines offered by health authorities are } \\
\text { too much. }\end{array}$ & $80(13.6)$ & $199(33.7)$ & $144(24.4)$ & $33(5.6)$ & $134(22.7)$ \\
\hline I would prefer avoiding multiple vaccines in one session. & $73(12.4)$ & $197(33.4)$ & $201(34.1)$ & $32(5.4)$ & $87(14.7)$ \\
\hline $\begin{array}{l}\text { I do not believe vaccines are useful; the diseases that they } \\
\text { prevent are not very serious. }\end{array}$ & $142(24.1)$ & $264(44.7)$ & $100(16.9)$ & $30(5.1)$ & $54(9.2)$ \\
\hline A vaccine recommended by the family physician is safe. & $32(5.4)$ & $82(13.9)$ & $269(45.6)$ & $110(18.6)$ & $97(16.4)$ \\
\hline A vaccine recommended by health authorities is safe. & $34(5.8)$ & $79(13.4)$ & $294(49.8)$ & $93(15.8)$ & $90(15.3)$ \\
\hline $\begin{array}{l}\text { Personnel that perform the vaccination allocate sufficient time } \\
\text { to dispel my doubts concerning vaccination. }\end{array}$ & $142(24.1)$ & $305(51.7)$ & $107(18.1)$ & $20(3.4)$ & $16(2.7)$ \\
\hline $\begin{array}{l}\text { Personnel that perform the vaccination have sufficient } \\
\text { knowledge about vaccines. }\end{array}$ & $139(23.6)$ & $313(53.1)$ & $90(15.3)$ & $18(3.1)$ & $30(5.1)$ \\
\hline $\begin{array}{l}\text { My pediatrician has sufficient knowledge about vaccines and } \\
\text { allocates sufficient time for me. }\end{array}$ & $115(19.5)$ & $297(50.3)$ & $81(13.7)$ & $24(4.1)$ & $73(12.4)$ \\
\hline $\begin{array}{l}\text { My pediatrician has sufficient knowledge about vaccines and } \\
\text { allocates sufficient time for me. }\end{array}$ & $165(28.0)$ & $337(57.1)$ & $47(8.0)$ & $16(2.7)$ & $25(4.2)$ \\
\hline $\begin{array}{l}\text { My pediatrician's opinion is very important in my decision } \\
\text { about vaccination. }\end{array}$ & $46(7.8)$ & $196(33.2)$ & $226(38.3)$ & $46(7.8)$ & $76(12.9)$ \\
\hline $\begin{array}{l}\text { My family physician's opinion is very important in my decision } \\
\text { about vaccination. }\end{array}$ & $44(7.5)$ & $133(22.5)$ & $305(51.7)$ & $49(8.3)$ & $59(10)$ \\
\hline $\begin{array}{l}\text { Mixed-combined vaccines (multiple vaccines in a single } \\
\text { syringe such as DTaP-IPV-Hib) limit the freedom to choose } \\
\text { acceptable vaccines. }\end{array}$ & $53(9.0)$ & $216(36.6)$ & $122(20.7)$ & $36(6.1)$ & $163(27.6)$ \\
\hline $\begin{array}{l}\text { Mixed-combined vaccines (multiple vaccines in a single } \\
\text { syringe such as DTaP-IPV-Hib) wear the immune system } \\
\text { excessively. }\end{array}$ & $67(11.4)$ & $213(36.1)$ & $86(14.6)$ & $30(5.1)$ & $194(32.9)$ \\
\hline
\end{tabular}




\begin{tabular}{|lll|}
\hline $\begin{array}{l}\text { Table 5. Information } \\
\text { Konya-2019* }\end{array}$ & $\begin{array}{l}\text { Number* } \\
\text { (n) }\end{array}$ & $\begin{array}{l}\text { Percentage } \\
\text { (\%) }\end{array}$ \\
\hline & 413 & 70.0 \\
\hline Family physician & 386 & 65.4 \\
\hline Internet, social media & 229 & 38.8 \\
\hline Religious sources & 227 & 38.5 \\
\hline Friends/family & 189 & 32.0 \\
\hline Pediatrician & 189 & 32.0 \\
\hline Anti-vaccination groups & 188 & 31.9 \\
\hline Religious opinion leaders & 187 & 31.7 \\
\hline $\begin{array}{l}\text { Print sources (book, magazine, } \\
\text { newspaper, etc.) }\end{array}$ & 116 & 19.7 \\
\hline Television & 115 \\
\hline Another trusted physician & 34 & 19.5 \\
\hline Public Health Center & 11 & 5.8 \\
\hline Other** & & \\
\hline${ }^{*}$ The participants marked more than one option. \\
**Aidin Salih (MD), uncle, dentist & & \\
\hline
\end{tabular}

side effects of vaccines (11). In one review based on data from 194 WHO Member States, vaccine safety concerns and fear of side effects, one of the most common reasons for vaccine hesitancy increased from $22.0 \%$ to $23.0 \%$, lack of knowledge of parent on benefit of immunization increased from $10.0 \%$ to $15.0 \%$, and religion, culture, gender and socioeconomic issues regarding vaccines increased from $9.0 \%$ to $12.0 \%$ over the three-year period from 2014 to 2016 (12).

Moreover, many studies show that families believe that although vaccines are beneficial, they also contain possibly harmful ingredients; families believe that vaccines may be more harmful than the diseases that they prevent; there are concerns about MMR in particular, families find multiple vaccines in one session to be risky; and families believe that health workers hide some negative aspects of vaccines (13-15).

Researchers concluded that the lack of information provided to mothers during pregnancy was effective in the emergence of these sentiments (13). In our study, one fourth of the parents stated that they were not sufficiently informed about vaccines by their gynecologist during pregnancy. The lack of knowledge of parents on vaccines is a problem that needs to be solved urgently to prevent vaccine refusal. The fact that vaccination is not seen as a priority issue in some specialties is a significant problem.

Every year, vaccines prevent 2.7 million measles, 2 million neonatal tetanus, and 1 million pertussis cases around the world. In 2017, WHO reported 14,000 measles cases in Europe, which increased to 83,000 cases in 2018 . Although the idea that vaccine-preventable diseases would not be seen again in the absence of vaccination was common among the respondents in our study, $87.0 \%$ of the measles cases in Europe were nonvaccinated individuals (16).
$56.0 \%$ of the families in our study refused vaccination due to religious reasons. Although it was not one of the top three reasons of vaccine refusal, religious reasons are still a matter of concern in terms of preventing vaccine refusal since they influence certain groups. In one study conducted in 13 countries from $6 \mathrm{WHO}$ regions including Muslim countries such as Saudi Arabia and Yemen, religious concerns were among the most significant reasons of vaccine refusal in most of the countries (17). Similarly, the fact that vaccines did not have halal certificate was found to be a reason for vaccine refusal in a study conducted by WHO and UNICEF with participants from 154 countries (18). Vaccine refusal due to religious reasons is a problem experienced not only in Muslim countries, but in countries where other religions are dominant as well. Failure to eliminate concerns of the society may be due to failure to involve civil society organizations and religious opinion leaders in decision mechanisms related to vaccination and exclusion of politicians or health professionals from the decision-making process of families refusing to have their children vaccinated due to religious incompatibility. This matter needs to be studied in more detail.

The vaccine-autism association continues to be a concern for parents. Thiomersal, which contains ethyl mercury, has been used as a preservative in some vaccines since the 1930s. However, the claims that the increase in the number of vaccines in the childhood vaccination schedule and the fact that some of these vaccines contain thiomersal increase the cumulative exposure of infants; and therefore, cause an increased number of nervous system development disorders such as autism, attention deficit/hyperactivity disorder, and delayed speech have been debated more and more in recent years (19-21).

In our study, one third of the families believed that vaccines cause autism. Studies from various countries showed no association between mixed vaccines, MMR in particular, and vaccines containing or not containing thiomersal in terms of spectrum disorders (19-21). Many scientific studies such as those mentioned above showed no difference between vaccinated and non-vaccinated children in terms of autism spectrum disorder prevalence, regardless of whether multiple vaccines are given together or each vaccine group is given within a vaccination schedule.

Similar to the results of other studies (15), $63.4 \%$ of the families in our study believed that vaccines weakened their children's immune system. Similarly, numerous studies show that the most significant concerns of vaccine refusers are related to the safety and side effects of vaccines $(14,22,23)$. There are also studies which reveal that families believe that side effects of vaccines are not as rare as claimed (24), a natural diet and healthy lifestyle provides better protection than vaccines (25), and undergoing the disease strengthens the immune system 
more than vaccines (24). It is believed that a significant lack of knowledge is behind concerns related to vaccines. This lack of knowledge maybe a result of insufficient number of scientific studies, insufficient understanding of existing studies or ineffective use of communication tools and techniques.

$47.0 \%$ of the families in our study were concerned about vaccines being produced overseas. Other studies also found that the belief that domestically produced vaccines would be safer was common $(15,26)$.

One study conducted in a hospital in Turkey revealed that $73.0 \%$ of health workers had concerns related to commercial activities and inducements of vaccine companies (27). In our study, about two third of the families believed that recommended vaccines served commercial benefits of pharmaceutical companies. It is believed that domestic and national vaccine production efforts in Turkey will be beneficial in terms of eliminating such concerns and increasing acceptance of vaccine by the society.

What really shapes the opinions of families regarding vaccines is their source of information. The most common sources of information in our study were health workers, family physicians in particular, followed by internet and social media. In one study from the US, parents were found to get their information about vaccines from health workers, followed by print materials such as books and magazines, and friends and relatives, and it was revealed that about half of families used the internet as their source of information (28). Although television, radio, and newspapers were mentioned as the sources of information in some studies, internet and social media are becoming more and more popular as an source of information on vaccines $(13,29)$. On the other hand, only $3.0 \%$ of the content about vaccines on the internet was found to be created by health professional (30).

In our study, religious opinion leaders and anti-vaccination groups were mentioned as sources of information by one third of the families. While families should be able to obtain accurate and reliable information from health workers such as family physicians, they get their information from other sources such as the internet, social media, friend circle, or religious opinion leaders, which is noteworthy.

Although the majority of the families reported that they were informed by health workers, $41.0 \%$ stated that health workers provided incomplete information about vaccines and did not mention negative aspects of vaccines. Although health workers were found to try to convince families to change their vaccine refusal decision, it was also found that their efforts to eliminate families' concerns fell short. Detailed studies are needed to reveal whether this is a result of a lack of confidence in health professionals or a lack of communication.

This study has some limitations. The study was conducted in family health centers. This led to the difficulty in persuasion of families who had to meet family health centers staff about vaccine refusal repeatedly. This was a limitation that negatively affected participation in the study.

\section{Conclusion}

In conclusion, although it is not representative of the entire country, the fact that vaccine refusal is so common in a large city reveals the extent of the danger. Particularly reasons behind families' distrust in vaccines should be studied in more detail. The families' lack of knowledge on vaccines needs to be eliminated. Parents need to be informed about the contents of vaccines using appropriate communication channels. Interventions aiming at vaccine refuser families need to be in line with cultural, historical, and religious values of the target group. In this context, detailed, long-term, multi-directional, well-planned, proactive communication strategies which use appropriate tools to reach the target group in cooperation with communication experts, opinion leaders, and civil society organizations are required. It is important to prefer vaccines that do not contain porcine gelatin in order to eliminate concerns of families who display religious incompatibility. Halal certification could be considered for vaccines.

\section{Ethics}

Ethics Committee Approval: The study was approved by the Local Ethical Committee (Drug and Non-Medical Device Research Ethical Committee of Necmettin Erbakan University Faculty of Meram Medicine, approval number: 05.10.2018/1514). The procedures were in line with the Helsinki Declaration.

Informed Consent: Informed consent was obtained from all participants at the time of survey application.

Peer-review: Externally peer-reviewed.

\section{Authorship Contributions}

Surgical and Medical Practices: L.S.D., Concept: H.I. L.S.D., Design: H.I., L.S.D., Data Collection or Processing: H.I., L.S.D., Analysis or Interpretation: H.I., L.S.D., Literature Search: H.I. Writing: H.I.

Conflict of Interest: No conflict of interest was declared by the authors.

Financial Disclosure: The authors declared that this study received no financial support.

\section{References}

1. Arısoy ES, Çiftçi E, Hacımustafaoğlu M, et al. Clinical practical recommendations for turkish national vaccination schedule for previously healthy children (National Vaccination Schedule) and vaccines not included in the schedule. J Pediatr Infect. 2015;9:1-11.

2. Centers for Disease Control and Prevention. Impact of vaccines universally recommended for children-United States, 1990-1998. MMWR. 1999;48:243-248. 
3. Bonanni P. Demographic impact of vaccination: a review. Vaccine. 1999;17(Suppl 3):120-125.

4. Getman R, Helmi M, Roberts H, Yansane A, Cutler D, Seymour B. Vaccine hesitancy and online information: the influence of digital networks. Health Educ Behav. 2018;45:599-606.

5. Gür E. Vaccine hesitancy - vaccine refusal. Türk Pediatri Ars. 2019;54:1-2.

6. Turkish Statistical Institute. Statistical indicators. 2019. Last Accessed Date: 15.03.2019. Available from: https:// biruni.tuik.gov.tr/medas/?kn=113\&locale $=\mathrm{tr}$

7. Larson HJ, de Figueiredo A, Xiahong Z, et al. The state of vaccine confidence 2016: global insights through a 67-country survey. EBioMedicine. 2016;12:295-301.

8. Gülgün M, Fidancı K, Karaoğlu $A$, et al. Investigation of 0-24 months vaccination status in children applied to pediatric outpatient clinic in a military hospital. Gülhane Med J. 2014;56:13-16.

9. Kurçer MA, Şimşek Z, Solmaz A, Dedeoğlu Y. Vaccınatıon rate and problems of $0-2$ aged chıldren and pregnant women in harrankapı health center regıon. Harran Üniversitesi Tıp Fakültesi Dergisi. 2005;2:10-15.

10. Yiğitalp G, Ertem M. Reasons for drop out of ımmunization in children aged between 0-12 months in Diyarbakır. TAF Prev Med Bull. 2008;7:277-284.

11. Karafillakis E, Dinca I, Apfel F, et al. Vaccine hesitancy among healthcare workers in Europe: a qualitative study. Vaccine. 2016;34:5013-5020.

12. Lane S, MacDonald NE, Martin M, Dumolard L. Vaccine hesitancy around the globe: Analysis of three years of WHO/ UNICEF Joint Reporting Form data-2015-2017. Vaccine. 2018;36:3861-3867.

13. Wachob DA, Body A. Social media's influence on parents' decision-making process of child vaccinations. Epidemiol Biostat Public Health 2019;16:1-5.

14. Rosso A, Massimi A, De Vito C, et al. Knowledge and attitudes on pediatric vaccinations and intention to vaccinate in a sample of pregnant women from the City of Rome. Vaccine. 2019;37:1954-1963.

15. Hough-Telford C, Kimberlin DW, Aban I, et al. Vaccine Delays, Refusals, and Patient Dismissals: A Survey of Pediatricians. Pediatrics. 2016;138:e2 0162127.

16. Bozzola E, Spina G, Russo R, et al. Mandatory vaccinations in European countries, undocumented information, false news and the impact on vaccination uptake: the position of the Italian Pediatric Society. Ital J Pediatr 2018;44:67.

17. DubéE, Gagnon D, Nickels E, Jeram S, Schuster M. Mapping vaccine hesitancy-Country-specific characteristicsof a global phenomenon. Vaccine. 2014;32:6649-6654.
18. Marti M, de Cola M, MacDonald NE, Dumolard L, Duclos P. Assessments of global drivers of vaccine hesitancy in 2014 - Looking beyond safety concerns. PloS One. 2017; 12:e0172310.

19. Taylor LE, Swerdfeger AL, Eslick GD. Vaccines are not associated with autism: an evidence-based meta analysis of Case-Control and cohort studies. Vaccine. 2014;32:36233629.

20. Hviid A, Hansen JV, Frisch M, Melbye M. Measles, Mumps, Rubella Vaccination and Autism A Nationwide Cohort Study. Ann Intern Med. 2019:170:513-520.

21. Jain A, Marshall J, Buikema A, Bancroft T, Kelly JP, Newschaffer CJ. Autism occurrence by MMR vaccine status among US children with older siblings with and without autism. JAMA. 2015;313:1534-1540.

22. Corben P, Leask J. Vaccination hesitancy in the antenatal period: a crosssectional survey. BMC Public Health. 2018; $18: 566$

23. Dubé E, Gagnon D, Ouakki M, et al. Measuring vaccine acceptance among Canadian parents: a survey of the Canadian Immunization Research Network. Vaccine. 2018;36:545-552.

24. Dubé E, Farrands A, Lemaitre $T$, et al. Overview of knowledge, attitudes, beliefs, vaccine hesitancy and vaccine acceptance among mothers of infants in Quebec, Canada. Hum Vaccin Immunother. 2019;15:113-120.

25. Kennedy AM, Brown CJ, Gust DA. Vaccine beliefs of parents who oppose compulsory vaccination. Public Health Rep. 2005;120;252-258.

26. Massimi A, Ross A, Marzuillo C, Prencipe GP, De Soccio $P$, Adama $G$, et al. Childhood vaccinations: a pilot study on knowledge, attitudes and vaccine hesitancy in pregnant women. Epidemiol Biostat Public Health. 2017;14:e126251-5.

27. Arıcan MD. Sağlık Çalışanları Arasında Aşılanmaya Genel Bakış, Aşı Kabulü ve Reddini Etkileyen Faktörler. Izmir University of Health Sciences Tepecik Training and Research Hospital Clinic of Family Medicine. Expert Thesis. 2019; İzmir.

28. Jones AM, Omer SB, Bednarczyk RA, Halsey NA, Moulton LH, Salman DA. Parents' source of vaccine information and impact on vaccine attitudes, beliefs, and nonmedical exemptions. Adv Prev Med. 2012;932741.

29. Topçu S, Almış H, Başkan S, Turgut M, Orhon FS, Ulukol $B$. Evaluation of childhood vaccine refusal and hesitancy intentions in Turkey. Indian J Pediatr. 2019;86:38-43.

30. Cuesta-Cambra U, Martínez-Martínez L, NiñoGonzález JI. An analysis of pro-vaccine and anti-vaccine information on social networks and the internet: visual and emotional patterns. El Profesional de la Información. 2019;28:e280217. 